\title{
The Feasibility of 'BEYB' Attacking Tactic Training in Futsal Game
}

\section{Benny Badru ${ }^{1 *}$}

${ }^{1}$ Penjaskesrek, Fakultas IImu Keolahragaan, Universitas Negeri Makasar, Makasar, Indonesia *e-mail: benny.b@unm.ac.id

\begin{abstract}
The game of futsal is a game that prioritizes speed so that the futsal is known as a sport that has high intensity. This study aims to develop a training model of BEYB attack tactics in futsal games. The research method uses the development method from Borg and Gall. The research was conducted at the Futsal Sports Hall, State University of Makassar. The subjects in this study were Futsal Athletes. Based on the data obtained, from the results of field trials and discussion of research results, it can be concluded that: through the validity test carried out using the expert justification test, the product is a training model to attack BEYB in futsal games as many as 40 training models. The attack tactics training model with patterns such as 2-2, 1-2-1, 3-1, and power play has been developed to be more varied and can be used in the attacking systems and formations that will be used. BEYB attacking training model can be applied in this futsal game, extracurricular teachers, especially futsal, should be reviewed so that athletes can do it according to their abilities and motor development.
\end{abstract}

Keywords: BEYB Attacking Tactic, Futsal Game

\section{Introduction}

Sports besides entertainment are also activities that can be used to maintain physical fitness (Astuti, 2017; Dinata et al., 2020; Fatchurrahman et al., 2019; Nur et al., 2019; Sumpena, 2017). Furthermore, sport is seen as a tool to uphold the name of the nation on the world stage. The peak achievements of sports cannot just be obtained but must go through a systematic and tiered process using a scientific approach (Apriantono et al., 2018). The pillars of national sports development in Indonesia begin with recreational sports and educational sports as the culmination is achievement sports (Almeida et al., 2019; Boonsom, 2020; Purnomo \& Hariono, 2020; Williyanto et al., 2020). In sports coaching, a coach must be able to develop a variety of training strategies that can make athletes move and train their basic motor skills because, in adolescence, their emotional level is not yet stable. Many things cause an athlete's lack of interest in the training process, including the lack of attractive presentation of training strategies by the coach (Agras et al., 2016; Astuti, 2017; Dupri et al., 2020; Guntoro et al., 2020; Sucipto, 2020). This of course requires a review of the training process. One of the important things that need to be mastered by a coach is about training variation, it must be realized that the lack of variation in each activity will lead to the boredom of an athlete which ultimately reduces interest. The interest of an athlete is quite large in the training process, so the effort that must be made is to create and present the activity in training to a combined training strategy situation so that training is more interesting and varied. One of the sports that requires training to achieve achievement is futsal.

Futsal was first played in Uruguay in 1930 when the "five-to-five" version. Futsal is an international terminology for the game, a combination of the Spanish "futbol sala", Futbol and Portuguese "Futebol de salao". If translated means indoor football. Futsal quickly became popular in South America, especially in Sao Paolo Brazil. Futsal has always been associated with a small version of football matches. But basically, it has a different game from soccer and has different dynamics from football, starting from the rules, the number of players, the field, and the ball used. For example, the goalkeeper in futsal can become a player, allowing the game to be dynamic and the team being able to score goals. The strategy of being a

\footnotetext{
${ }^{*}$ Corresponding author.
}

Received October 17, 2020; Accepted April 24, 2021; Available online September 25, 2021

Copyright @ 2021 by Author. Published by Universitas Pendidikan Ganesha. 
goalkeeper as a player is usually used during last-minute matches and when the team is losing it aims to make the match score change (de Freitas et al., 2017; Duncan et al., 2018). Indonesia has enough strong capital to develop Futsal achievements (Nugroho \& Tomoliyus, 2018). Starting from fanaticism, the number of Futsal fans in this country is very large. Since its introduction over ninety years ago with official regulations, Futsal has become popular. Until now, Futsal has always been transformed into a sport that has mushroomed for all groups, especially in big cities in Indonesia. So many Futsal competitions have been held on a local, national and international scale. Whether played by amateur clubs or professional clubs. And so it also happened to Futsal schools, which were originally only for a hobby, but in the end, were able to make the Indonesian nation proud. In general, all Futsal teams from schools, universities, amateur clubs, professional clubs, and even the national team strive to improve their performance (Aliyyah et al., 2020; Rahman, 2018; Satrio \& Winarno, 2019).

The choice of strategy to be applied during the match by the coach also affects the team's success in attacking. Coaches are required to quickly identify events that occur during the match. If the attack strategy that is implemented does not work well, the coach must quickly find a solution or change the strategy. Finding solutions and changing strategies during the match requires the coach to have a varied attack strategy model. So that the coach can implement an attack strategy according to the abilities of each player and the conditions during the match. Based on the results of the needs analysis carried out by researchers in the futsal subject, the following were found: 1) Only $10 \%$ of futsal athletes know the principles of attacking in the futsal game; 2) Only $15 \%$ of futsal athletes know the principles of defending futsal. 3) $20 \%$ of futsal athletes know the attack zone system in playing futsal; 4) $25 \%$ of futsal athletes know the defensive zone system in playing futsal. Therefore, it is necessary to develop an attacking model in futsal games with the aim of playing on the field to be dynamic and game tactics that are difficult for the opponent to guess. This research is strengthened by research Méndez-Domínguez at all with title Goals scored and received in 5vs4 GK game strategy are constrained by critical moment and situational variables in elite futsal. The result is a coach must be able to see the correct futsal playing strategy in a match so that he can win the match.

Based on these findings, futsal athletes need to provide an understanding and create an attacking training model in the futsal game, the goal is that all players can do and bring out all their best abilities in playing and in arranging attacks through more varied game patterns in playing so that many goals are created (Ahmed et al., 2017). to the opponent's goal so that later it is hoped that the research and development model research carried out can provide a new training model that can be used in futsal training and ultimately provide the best results for the newest and quality training model, with the attack training model that is to improve the quality and quality of playing futsal. This study aims to develop a training model of BEYB attack tactics in futsal games

\section{Method}

In general, the results of development research are to produce new products that will later be used in training activities to make it easier for trainers to deliver training materials and make it easier for trainers or teaching staff to achieve the expected training results. The research was conducted at the Futsal Sports Hall, State University of Makassar. The subjects in this study were Futsal Athletes in Makassar City.

The final result of this development research is the BEYB attack training model in futsal games in the form of a complete training design with product specifications as well as testing the effectiveness of the training model created so that it can improve the skills of futsal players in attacking in futsal games and can also be used as a guide in training. The research and development in this exercise use Borg and Gall's ten-step Research \& Development (R \& D) development model. 


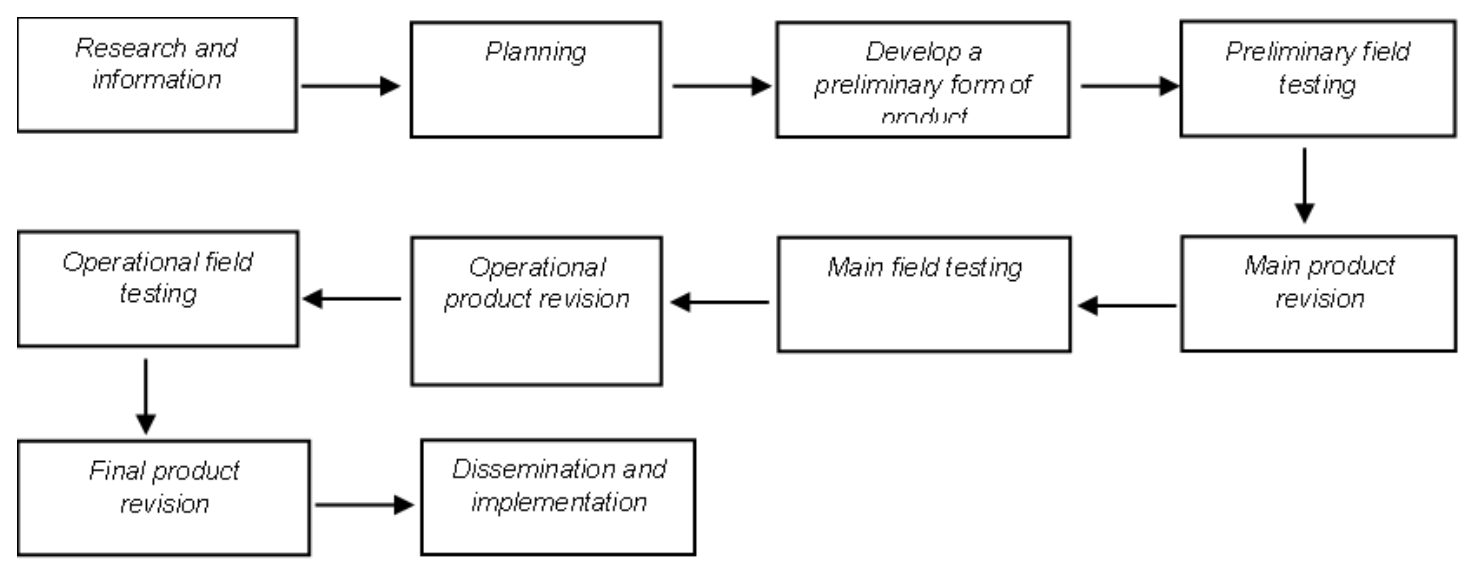

Figure 1. Instructional Design Rand D (Borg \& Gall, 1984)

Conceptually, the research and development approach to the Borg and Gall model includes 10 general steps, the adaptation is realized in the form of target technical planning and the types of activities to be carried out in each stage. If the ten steps of research and development are followed correctly, it will produce an accountable training product. The final result of the research and development activities is the 'BEYB' attack training model in the Futsal game. Of course, the final results of this research and development will produce a new training model design complete with product specifications, so that it can be used as a guide in the training process.

\section{Result and Discussion}

\section{Results}

Overall, two general objectives will be revealed in the preliminary study or need analysis, namely: 1) How important is the development of an attacking training model in the Futsal game. 2) What obstacles and supports are found in the development of the attacking training model in the Futsal game. The training model that will be developed is the result of problems found by researchers in the field through observations and interviews as well as personal experiences as trainers and lecturers in futsal subjects. Based on observations and interviews conducted by researchers, general objectives are obtained from developing the BEYB training model in the Futsal game, in addition to some general objectives the researcher can also find out some of the characteristics of the subject from the training model to be developed.

The results of the data that the researcher has collected through interviews and field observations, are then processed and described in writing and a conclusion is drawn, while some conclusions from the results of interviews and field observations can be described as follows, that the assault exercises that have been carried out so far are less varied and of their nature too monotonous because they have not used training models that combine various kinds of movements and physical exercises so that the training process can produce maximum output, namely being skilled and also fit (Aliyyah et al., 2020; Satrio \& Winarno, 2019). The introduction of attack tactics patterns in training is limited to a few simple movements without updating information about the current development of modern futsal. The coaches have not yet optimized the players' abilities and the facilities and infrastructure around the field because training is focused on the instructor, not on athletes or students. The results of the preliminary study or field findings are further described and analyzed so that these results are descriptive and analytical, concerning the objectives of the preliminary study. The results of the needs analysis and field findings obtained by researchers is shown in Table 1. 
Table 1. The Results of Need Analysis and Findings

\begin{tabular}{|c|c|c|}
\hline No & Question & Findings \\
\hline 1 & $\begin{array}{l}\text { What is taught in Futsal } \\
\text { practice? }\end{array}$ & $\begin{array}{l}\text { The trainer has taught some form of exercise } \\
\text { material, but it is not optimal in its practice. }\end{array}$ \\
\hline 2 & $\begin{array}{l}\text { Is Futsal training material } \\
\text { always provided every year? }\end{array}$ & $\begin{array}{l}\text { Futsal material is not always varied by coaches } \\
\text { because it is not updated in the latest information } \\
\text { about futsal coaching. }\end{array}$ \\
\hline 3 & $\begin{array}{l}\text { What facilities and } \\
\text { infrastructure are used for the } \\
\text { Futsal training model? }\end{array}$ & $\begin{array}{l}\text { The facilities and infrastructure used in futsal } \\
\text { training are balls, cones, markers, whistles, } \\
\text { strategy boards, vests, and Futsal fields. }\end{array}$ \\
\hline 4 & $\begin{array}{l}\text { How is the enthusiasm of } \\
\text { athletes/students participating } \\
\text { in each Futsal exercise? }\end{array}$ & $\begin{array}{l}\text { Athletes/students are enthusiastic about } \\
\text { participating in every Futsal training session. }\end{array}$ \\
\hline 5 & $\begin{array}{l}\text { What efforts have been made } \\
\text { so that athletes/students are } \\
\text { interested in participating in the } \\
\text { training process? }\end{array}$ & $\begin{array}{l}\text { The futsal coaches have tried to make athletes } \\
\text { interested and enthusiastic in participating in each } \\
\text { training process by incorporating elements of } \\
\text { competition. }\end{array}$ \\
\hline 6 & $\begin{array}{l}\text { What does each Futsal training } \\
\text { model need? }\end{array}$ & $\begin{array}{l}\text { In general, coaches and athletes need a variety of } \\
\text { Futsal training models, especially in attack } \\
\text { training. }\end{array}$ \\
\hline
\end{tabular}

The preparations carried out by the researcher were: 1) The tools used in this study were balls, cones, markers, whistles, and vests; 2) The field or area used for the conduct of research must pay attention to the safety factor (safety) and the perfection of the field and away from dangerous objects, 3) The sequence of game models ranging from warm-up games to core games is already systematic, 4) The training models presented have their characteristics leading to Futsal practice. 5) The involvement of the coach to be an active part of the children/athletes in training is needed so that the players/athletes are enthusiastic, and become more focused during training. 6) Based on the needs analysis and product revisions, 40 attack training models were produced in the Futsal game which was declared final. 40 attack training models were produced is presented in Table 2.

Table 2. Attack Training Models Were Produced

Description
player A passes to B then player B passes to
player $\mathrm{C}$ then player $\mathrm{C}$ passes to player $\mathrm{D}$
backpasses to player $\mathrm{C}$ runs without the ball
Player $\mathrm{C}$ immediately makes a cross pass to
the far post of player $\mathrm{A}$ who runs without the
ball into the middle of shooting

Figure 3. Attacking Training Model 


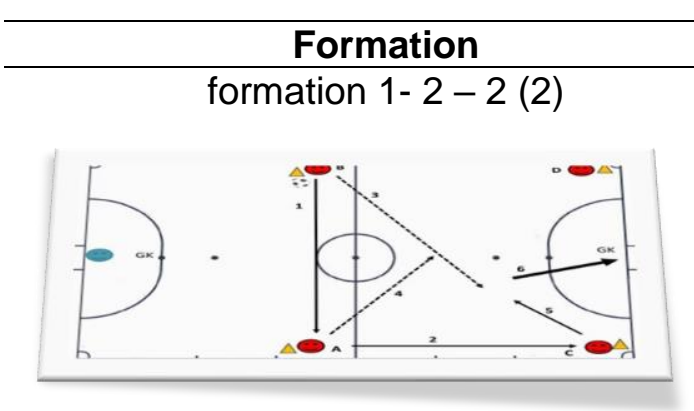

Figure 4. Attacking training model formation 1- 2 - 2 (3)

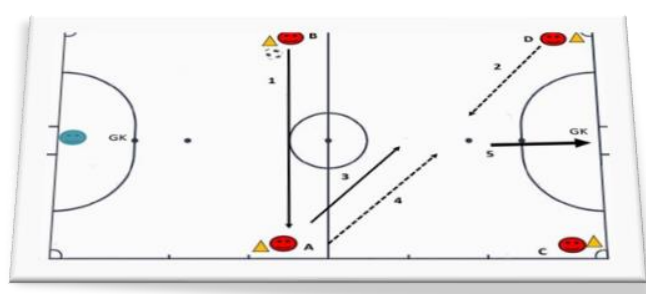

Figure 5. Attacking training model formation 1- 2 - 2 (4)

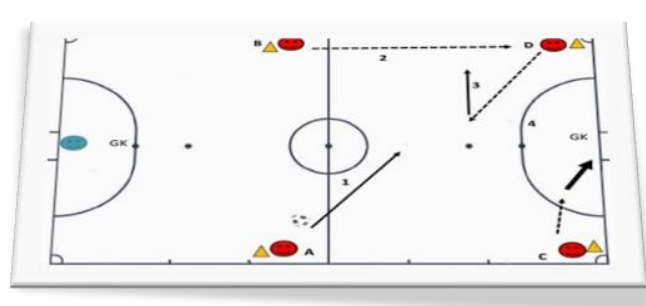

Figure 6. Attacking training model formation 1- $2-2$ (5)

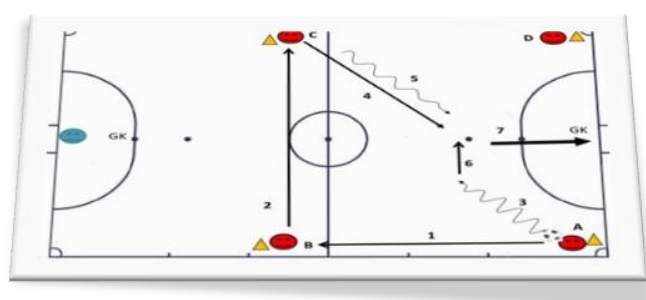

Figure 7. Attacking training model formation 1- 2-2 (6)

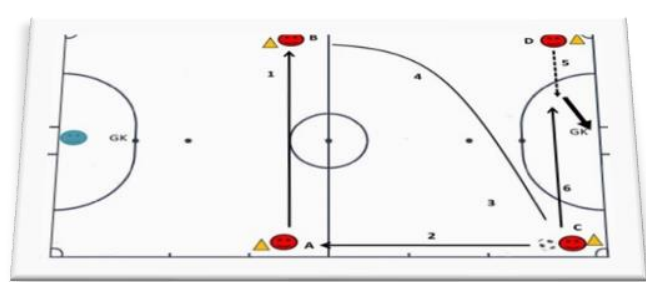

Figure 8. Attacking training model formation 1- $2-2$ (7) player B passes to player $A$, then Player $A$ passes to player $C$, then player $B$ moves across to the middle, then player $A$ moves across to the middle, then player short passes across to player B, finally player B shoots.

The first ball flows in player $B$ then passes to player $A$, and player $D$ runs to the middle, then player $A$ passes to player $D$ then player $A$ runs to the middle then player A shoots.

The first ball flow in player A passes to player $D$ who runs into the middle to receive a pass from player $A$, then player $B$ runs forward to get ready to receive a short pass from player $D$ then player $D$ short passes to player $B$, then Player $B$ makes a true pass to player $C$ who runs to pick up the last ballplayer $C$ shoots.

The first ball flows in player $A$ then passes to $B$ then player $B$ passes to player $C$, player $A$ runs into the middle and gets ready to receive the ball from player $C$ and passes to player $A$ who has entered the middle, then Player $C$ enters the middle and player A short pass to player $\mathrm{C}$ who runs in the middle of the last player $\mathrm{C}$ to shoot.

The first ball flows to player $C$ then passes to player $A$, then player $A$ passes to player $B$, then player $B$ passes a long pass to player $C$ then player $\mathrm{C}$ holds the ball then passes straight to player $D$. Then player $D$ picks up the ball and shoots. 


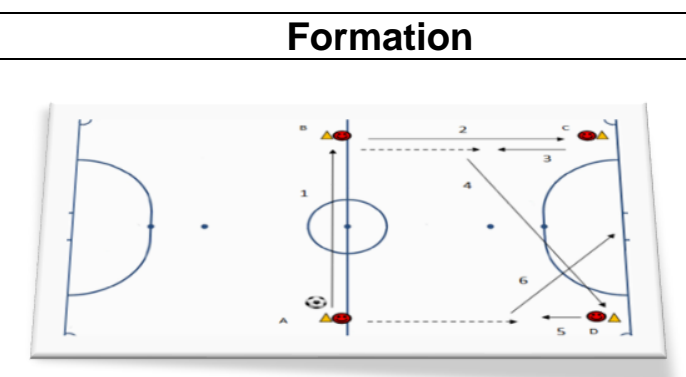

Figure 9. Attacking training model formation 1- 2 - 2 (8)

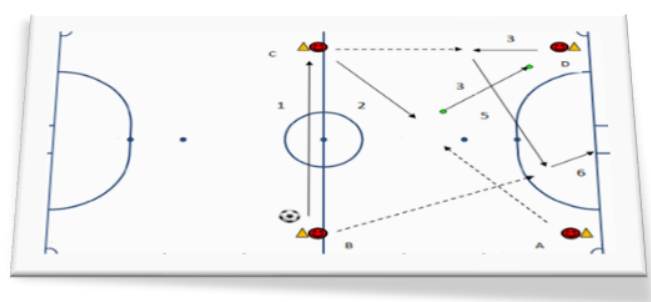

Figure 10. Attacking training model formation 1- 2 - 2 (9)

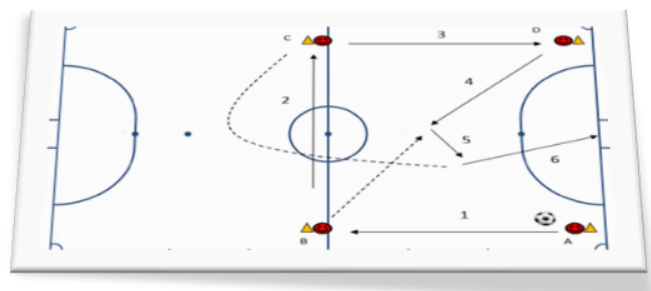

Figure 11. Attacking training model formation 1- $2-2$ (10)

Formasi 1-1-2-1

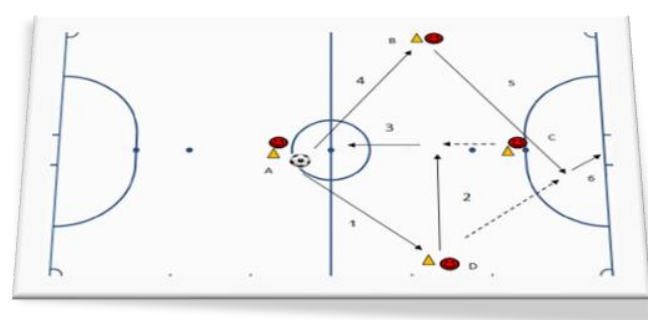

Figure 12. Attacking training model formation 1-1-2-1(11)

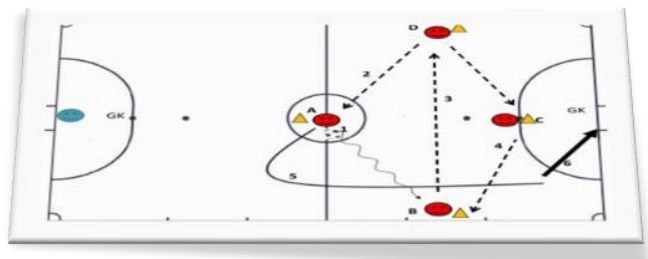

Figure 13. Attacking training model formation 1- 1-2-1 (12)

\section{Description}

Player A gives a pass to player $\mathrm{B}$, then player $B$ gives the ball to player $C$, and player $C$ passes back to player $B$, after controlling the ball player $B$ then gives a cross pass to player $D$ to the opponent's defense circle, and player D short passes to player A who runs forward, player A shoots towards the goalkeeper

Player B passes to player C, Player $\mathrm{C}$ crosses the middle where player $A$ runs towards the middle, Player A receives the ball by directing the ball to Player D followed bypassing, Player $D$ back passes to Player $C$ who runs to pick up the ball, Then Player $C$ performs an accurate cross pass towards the far-field where player $B$ runs to pick up the ball, Player B completes the pass by strapping or shooting at goal

Player A passes to player B, then player B passes to player $C$, player $C$ passes to player $D$, then player $D$ passes to the area outside the penalty circle towards player $\mathrm{B}$, then player $B$ comes towards the ball, and player $C$ moves without the ball towards the ball, then player $B$ gives a short pass to player $\mathrm{C}$ and player $\mathrm{C}$ shoots.

player $A$ passes to player $D$ player $D$ passes to player $C$ who moves in the center area of player $C$ then passes a short pass to player $A$ player A passes to player B, player B passes to player $D$ who runs in the left area of the goal player $D$ runs to pick up the ball then do the finishing touches by shooting.

player A dribbles to player B's position, player $B$ shifts to player D's position, player D shifts to player C's position, player A passes to player $\mathrm{C}$ who has moved positions, player $\mathrm{C}$ short passes to player $D$ who overlaps forward then shoots into the goal. 


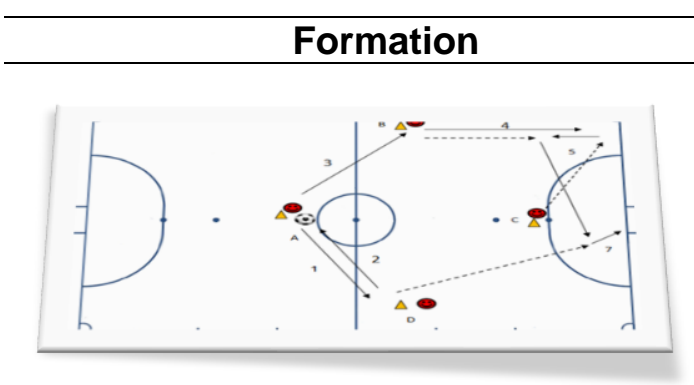

Figure 14. Attacking training model formation 1- 1-2-1 (13)

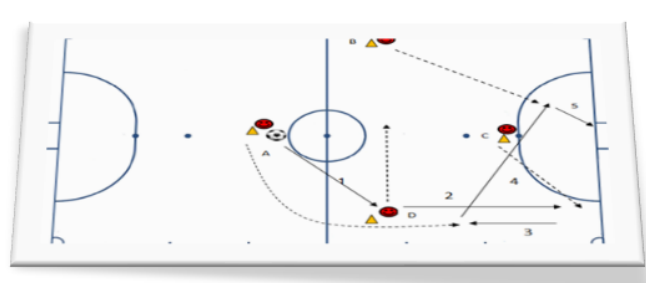

Figure 15. Attacking training model formation 1-1-2-1(14)

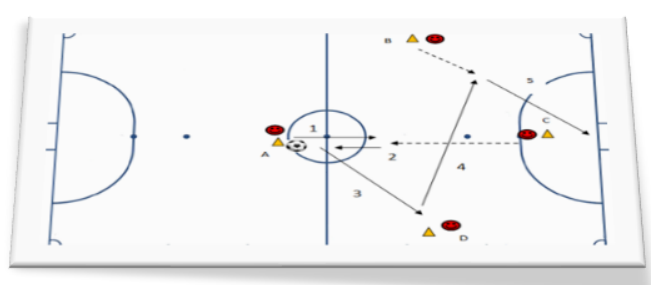

Figure 16. Attacking training model formation 1- 1-2-1 (15)

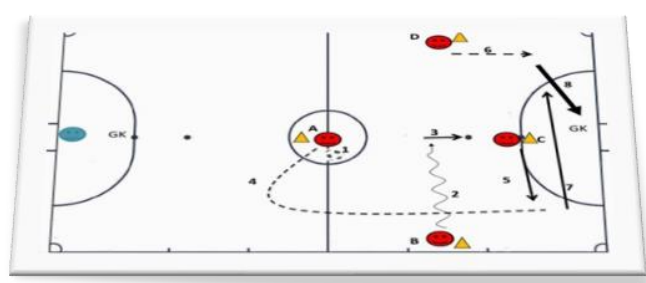

Figure 17. Attacking training model formation 1- 1-2-1(16)

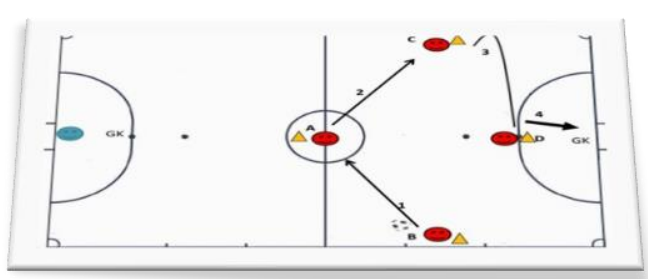

Figure 18. Attacking training model formation 1- 1-2-1 (17)

\section{Description}

player $A$ passes to player $D$, then player $D$ backpasses to player $A$, player $A$ passes to player $B$, player $B$ passes to player $C$ who opens the space in the right corner, then player $\mathrm{C}$ does a backpass combination with player $\mathrm{B}$ and continues shooting to the far post where player $C$ runs, last player $C$ makes the finishing touch by pleasing or shooting at goal.

player $A$ passes to player $D$, player $D$ passes to player $\mathrm{C}$ who opens space in the left corner, player $C$ does a backpass to player $A$ who overlaps past player $D$ who runs into the middle to close the opponent's space, player A continues by shooting at the far post where player B runs, last player B makes the finishing touches pleasing to the goal.

player $A$ passes to player $C$ who picks up the ball player $C$ does a backpass to player $A$ returns then player $A$ passes to player $D$ player $D$ immediately crosses right to player $B$ while running to receive the ball immediately shoots into the goal.

Player A passes to player B, player B dribbles small to the middle of the field, then player $B$ passes to player $C$, Player $A$ runs fast towards the right side, Player $C$ short passes to player $A$ who has run to the right side, player $D$ runs fast forward left side, Player A crosses to player D, Player $\mathrm{D}$ does the shot.

Player B passes to Player A, then Player A passes to Player $C$, then Player $C$ Long Passes to Player D, finally, Player D shoots. 


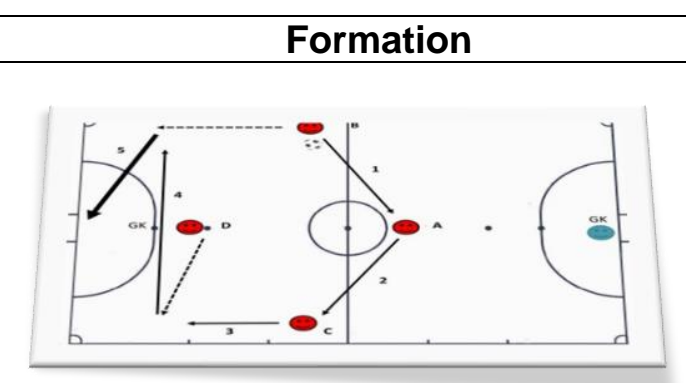

Figure 19 Attacking training model formation 1-1-2-1 (18)

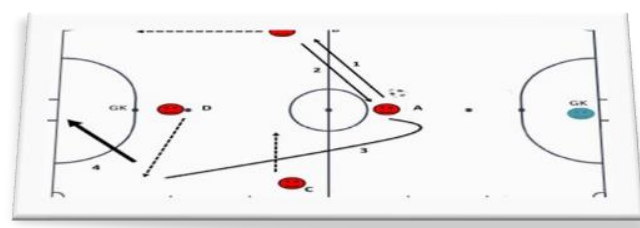

Figure 20. Attacking training model formation 1- 1-2-1 (19)

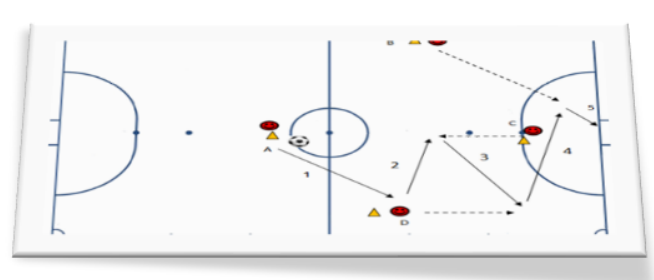

Figure 21. Attacking training model formation 1- 1-2-1 (20)

Formasi 1-3-1

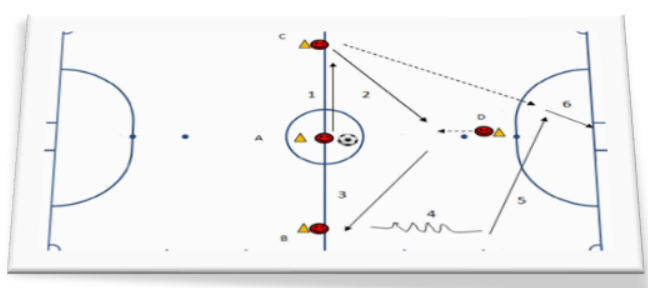

Figure 22. Attacking training model formation 1-3-1 (21)

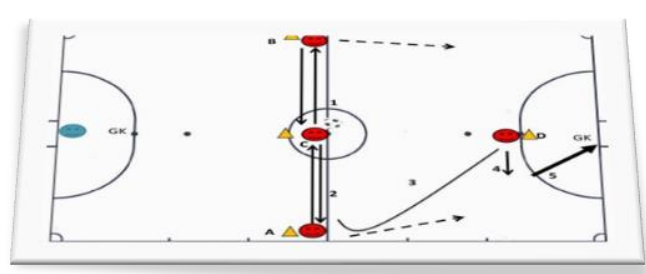

Figure 23. Attacking training model formation 1- 3-1 (22)

\section{Description}

Player B passes to Player A, Player A passes to Player $C$, Player $C$ passes to Player D who runs to open space, Player D passes to Player $B$ who moves forward, Player B makes shooting.

Player A passes to Player B, Player B passes back to Player A, Player A Long passes to Player $D$ who runs to open space, Player $D$ Dribbles small \& does the shooting.

Player A passes to player D, player D passes to player $\mathrm{C}$ who picks up the ball, Player $\mathrm{C}$ does a combination of passing with player $D$ who runs towards the front, Player $D$ shoots at the far post and Player $B$ is ready to receive the ball followed by pleasing to the goal.

Player A passes to player C, Player C passes to the middle of player $D$ with the aim of threatening, followed by player $D$ bypassing to player B. Player B dribbling at straight forward speed, then passing to player $\mathrm{C}$ who is already running and ready waiting at the far post Player A finishes by shooting / pleasing to the goal.

Player $C$ passes to $B$, then player $C$ passes back to player $C$, then player $C$ passes to player $A$ and then back passes how many times with player $\mathrm{C}$, then player $\mathrm{A}$ long passes to Player $D$, then player $D$ short passes to Player A who runs forward going forward to break through the opponent's defense with player B, last player A shoots 


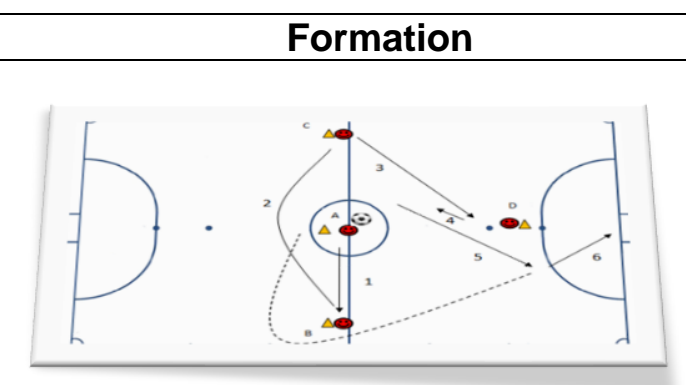

Figure 24. Attacking training model formation 1-3-1 (23)

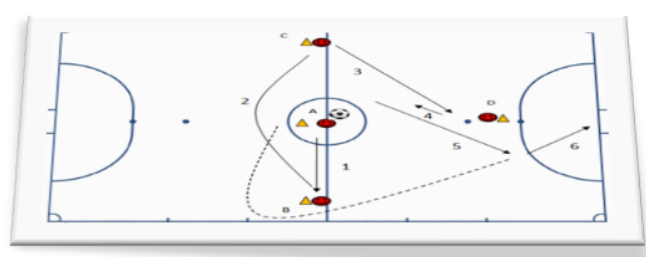

Figure 25. Attacking training model formation 1-3-1 (24)

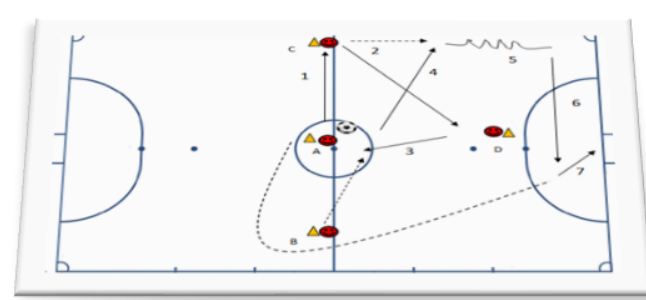

Figure 26. Attacking training model formation 1- 3-1 (25)

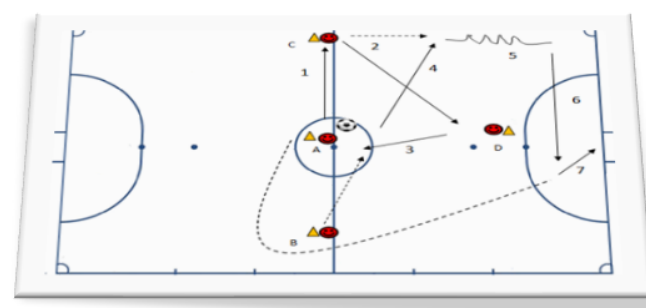

Figure 27. Attacking training model formation 1-3-1 (26)

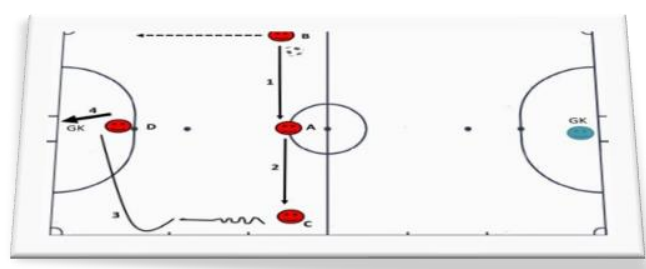

Figure 28. Attacking training model formation 1-3-1 (27)

\section{Description}

Player A passes to player B, Player B makes a long pass to player $\mathrm{C}$, Player $\mathrm{C}$ passes to the middle towards player $D$, Player $D$ passes back to player $C$ then, Player $C$ crosses ass to player A who has overlapped, Player A runs opens the space to receive the ball well which ends with shooting at goal.

Player A passes to player B, Player B long passes to player $C$, Player $C$ dribbles with last speed, Player $C$ short passes to player $D$ who opens space, Player D makes a combination pass with Player $C$ who runs towards the middle, Player $\mathrm{C}$ completes by shooting at goal, with player A running in anticipation of the ball.

Player A passes to player C, Player C passes towards the middle of player $D$ to threaten which is followed by player $D$ with a back pass to player B who runs into the middle, Player B passes at player $C$ Then player $C$ dribbles the ball at a speed which continues with a pass or cross pass to Player A who is overlapping, Player A is shooting or pleasing to score.

Player A passes to player C, Player C passes towards the middle of player $D$ to threaten which is followed by player $D$ with a back pass to player $B$ who runs into the middle, Player B passes at player $C$ Then player $C$ dribbles the ball at a speed which continues with a pass or cross pass to Player A who is overlapping, Player A is shooting or pleasing to score.

Player B passes to player B, Player B passes a long pass to player $\mathrm{C}$, Player $\mathrm{C}$ dribbles with last speed, Player $C$ short passes to player $D$ who opens space, Player $D$ makes a combination pass with player $\mathrm{C}$ who runs towards the middle, Player $\mathrm{C}$ completes by shooting at goal, with player $A$ running in anticipation of the ball. 


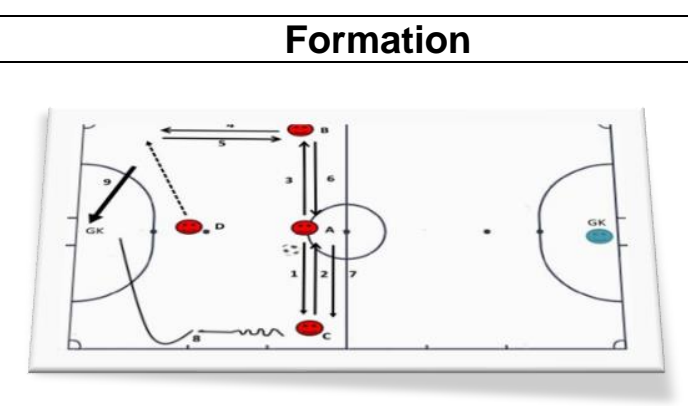

Figure 29. Attacking training model formation 1- 3-1 (28)

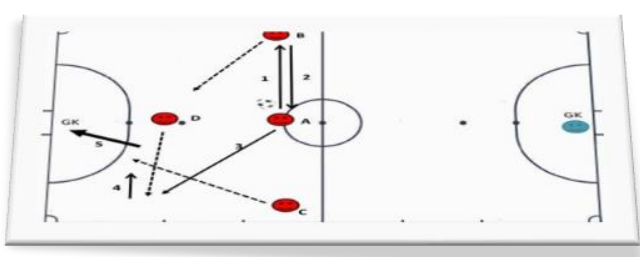

Figure 30. Attacking training model formation 1- 3-1 (29)

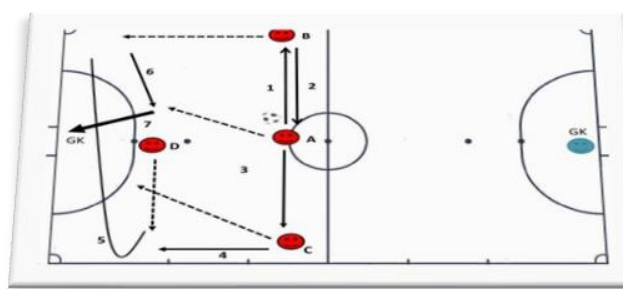

Figure 31. Attacking training model formation 1- 3 - 1 (30)

\section{Formation Power play}

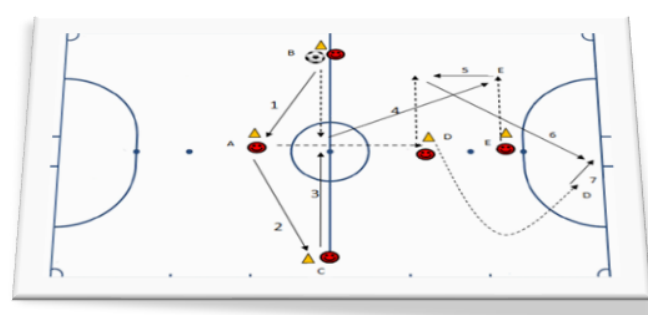

Figure 32. Power play attacking training model (31)

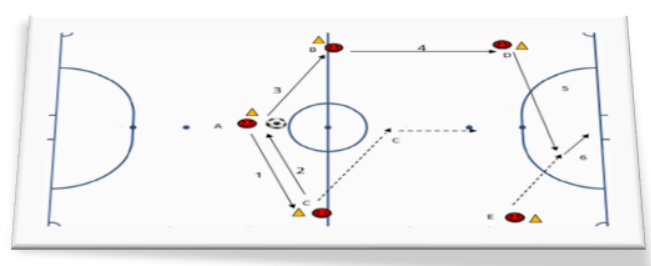

Figure 33. Power play attacking training model (32)

\section{Description}

Player A passes to player $C$, Player $C$ passes back to player A, Player A passes to player B, Player $B$ passes to player $D$ who moves out the right side, Player $D$ passes back to player $B$, Player $B$ passes to player A, Player A passes to player $C$, Player $C$ is dribbling forward then across passes to player $D$ who is standing, lastly Player D shoots.

Player A passes to player B, Player B passes back to player $A$, then player $B$ moves to the middle of the field, Player A passes to Player $D$ which opens the space on the left, Player $D$ short passes to Player $C$ who moves into the middle, lastly Player $\mathrm{C}$ do shooting.

Player A passes to player B, Player B passes back to player $A$, then player $B$ moves to run straight ahead. Player A passes to player C, Player $C$ passes to player $D$ who moves to open space on the right. Player $D$ Long passes across to Player B who moves forward on the left, Player B short passes to Player A who moves into the middle. Finally, Player A shoots.

player B passes to player A, player A passes to player $\mathrm{C}$, player $\mathrm{B}$ runs without the ball to receive the back pass from player $C$, player $B$ passes to player $E$ who has opened up space, then player $A$ runs towards player $E$ to receive the back ball pass from player $E$, then player $A$ makes a pass towards the far post, player $D$ opens space for finishing touches by pleasing to the goal.

player $A$ passes to player $C$, player $C$ passes back to player $A$, then player $A$ passes to player $\mathrm{B}$, player $\mathrm{B}$ continues passing to player $D$, player $D$ makes a cross pass to player $E$ who runs from outside the penalty box, player $E$ runs to pick up the ball to make the final pleasing touch to the goal, with player $\mathrm{C}$ anticipating the ball by standing in the center area / second penalty point. 


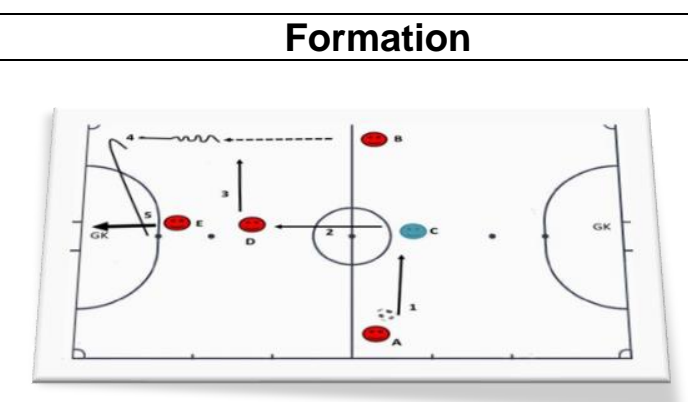

Figure 34. Power play attacking training model (33)

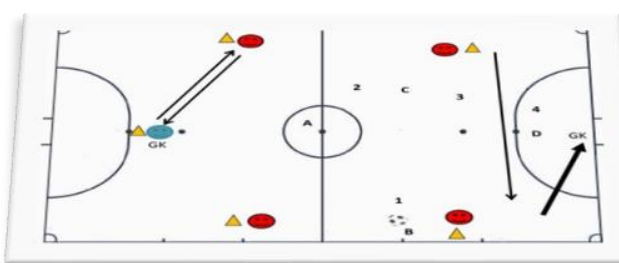

Figure 35. Power play attacking training model (34)

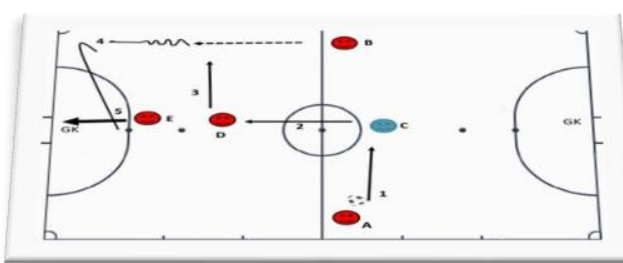

Figure 36. Power play attacking training model (35)

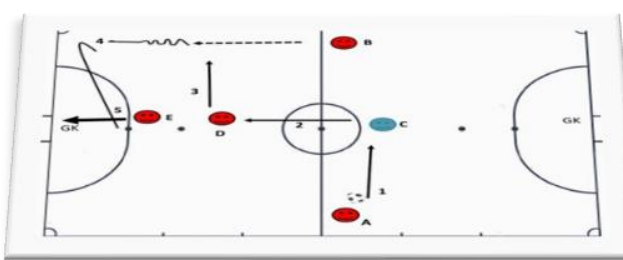

Figure 37. Power play attacking training model (36)

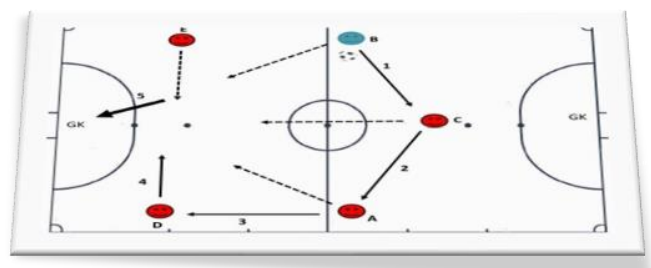

Figure 38. Power play attacking training model (37)

\section{Description}

player $A$ passes to player $C$, player $C$ passes to player $D$, player $D$ continues short passing to player B who runs forward, player B does dribbling then does a long cross to player $\mathrm{E}$ who is in the middle, finally player $E$ shoots.

player $A$ passes to $C$, then back passes back to player $A$, Player $D$ \& $E$ runs together closer to player $A$, then player $C$ runs forward, Player $A$ long passes to player $C$ who has run forward, player B runs forward, Player C true pass to player B, last player B shooting.

player A passes to player $C$, player $C$ passes to player $D$, player $D$ continues short passing to player B who runs forward, player B does dribbling then does a long cross to player $\mathrm{E}$ who is in the middle, finally player $E$ shoots.

player A passes to player $C$, player $C$ passes to player $D$, player $D$ continues short passing to player B who runs forward, player B does dribbling then does a long cross to player $\mathrm{E}$ who is in the middle, finally player $E$ shoots.

player A passes to player $C$, player $C$ passes to player $D$, player $D$ continues short passing to player B who runs forward, player B does dribbling then does a long cross to player $E$ who is in the middle, finally player $E$ shoots. 


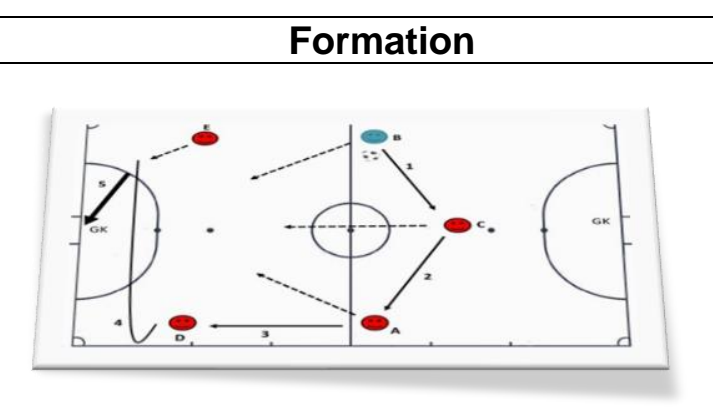

Figure 39. Power play attacking training model (38)

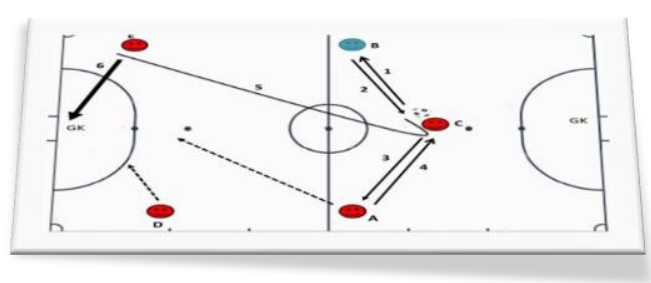

Figure 40. Power play attacking training model (39)

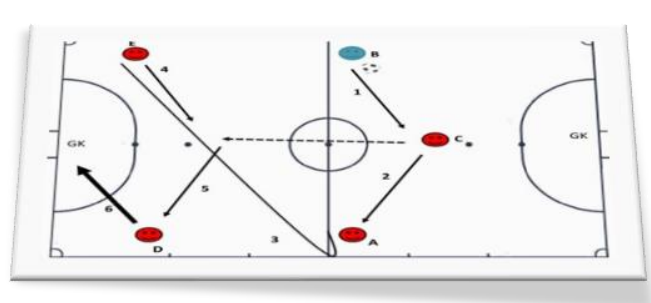

Figure 41. Power play attacking training model (40) player $B$ passes to player $C$, player $C$ passes to player $A$, player $A$ passes to player $D$, player $D$ passes a long cross to player $E$ who runs into the right side, lastly player E shoots.

player $C$ passes to player $B$, player $B$ passes to player $C$, player $C$ passes to player $A$, player $A$ passes to player $C$, player $C$ long passes to player E, lastly Player E shoots.

player $B$ passes to player $C$, player $C$ passes to player $A$, player $A$ long passes to player $E$, player $\mathrm{E}$ passes short to player $\mathrm{C}$, which moves into the middle, Player continues to pass to player D, last player D shoots.

\section{Discussion}

Expert tests conducted by three experts have several constructive suggestions for perfecting the BEYB attacking training model in the Futsal game including 1) There is a need to add a goalkeeper symbol in the training model. 2) Figure legend/symbol on each model must have a clear direction and purpose of its movement. 3) There needs to be a combination of skills training with the formation of physical components. 4) Players/futsal athletes must know the zone of attack. 5) The time lag required for demonstration/practice from one training model to the next training model takes how long it takes to implement. 6) Movements must start from easy to difficult levels, namely movements starting from the basics, variations, and combinations and complexity of movements, 7) Implementation instructions must be made clear so that they are easy to understand, 8) Figure models must be clear according to the correct movements, 9) BEYB training models must use safe and comfortable equipment. 10) The movement being trained must be comprehensive from the upper and lower body parts, the dominant and non-dominant body.

Then the next development stage is to use the model in small and basic groups, the results are as follows: 1) all variations can be applied, but the training model must be adjusted from easy to difficult levels so that the ability can increase quickly. 2) The need for good physical abilities such as coordination (especially eye and leg coordination), strength, agility, balance, explosive power, endurance, and speed. 3) It is necessary to have examples of movements in advance in each training model so that it is easy to understand the series of movements. 4) There needs to be adequate heating to support the training process 5) The 
use of adequate facilities and infrastructure that is safe and comfortable can affect the quality of skills training, 6) Repetition of the training model must be done at least three times so that the research subject can carry out their duties smoothly so that the output of the developed model can be accounted for and produce mature skills, 7) The time lag between instruction and implementation must be tailored to the needs. 8) Providing clear regulations and implementation limits will make it easier to coordinate research subjects.

One of the differences that is considered important in this study is the development of a futsal attack strategy carried out, namely the 1-2-2, 1-1-2-1, and 1-3-1 strategies and power play, while the research conducted by Ashari, RF, \& Adi, S in 2019 only developed a 1-3-1 attack strategy. After the results of the development of the BEYB attack training model product in the Futsal, the game has been tested on a small scale and have been revised, the next step is to conduct large group trials. Based on the results of limited trials (small group trials) that have been evaluated by experts, then the researchers revised the initial product and obtained 40 training models to attack BEYB in the Futsal game with a wide variety of variations, combinations, and complexity of movements from easy training models to training models difficult to use in large group trials. The process of developing this attack tactic aims to make players and coaches get alternatives in the futsal game and it is in accordance with the developed theory that the BEYB tactics developed can be used as an alternative in futsal games to avoid games that have been read by other teams.

The next step after the model underwent a second stage revision of 3 experts and small group trials then continued by testing the product in a large group using 120 research subjects, 60 research subjects were used as the treatment group and 60 research subjects were used as the control group. A treatment group is a group of research subjects who are given exercise treatment with the developed training models, namely the BEYB training model in the Futsal game. The treatment is carried out within a period of 3 months, starting from March to June with a total of 10 meetings. During the study, the treatment group was given 7 BEYB training models at every meeting. Before giving treatment, the research subject was in the initial test using the test instrument to attack the Futsal game of the research subject before and after treatment.

Finally, the effectiveness test, the assessment data of 60 research subjects on the effectiveness of the BEYB attack training model in the Futsal game is shown in the following table. Based on the results of the output using SPSS 21, the average value of attack before being given the BEYB attacking training model is 23.47 and after being given treatment with the attacking training model 35.27 means that the average value of the BEYB attacking model in the Futsal game has an increase. In the significance test of the difference with SPSS 21, the results of $\mathrm{t}$-count $=-71.065, \mathrm{db}=59$, and $\mathrm{p}$-value $=0.00<0.05$ which means there is a significant difference in the attack training model before and after being given the $B E Y B$ training model in the Futsal game. Based on this information, it can be said that the BEYB training model in the Futsal game developed is effective and can improve attacking practice in Futsal games. The results of this study are supported by previous research that the development of an effective futsal strategy can improve a player's ability to adapt to the current match (Ashari \& Adi, 2019; Cosmin \& Mircea, 2014).

\section{Conclusions and Suggestions}

Based on the data obtained, from the results of field trials and discussion of research results, it can be concluded that through the validity test carried out using the expert justification test, the product is a training model to attack BEYB in futsal games as many as 40 training models. The attack tactics training model and power play has been developed to be more varied and can be used in the attacking systems and formations to be used. The suggestion from this research is that in applying the BEYB attacking training model in this futsal game, extracurricular teachers, especially futsal, should be reviewed so that athletes can do it according to their abilities and motor development. 


\section{Acknowledgements}

Thanks to the Rector and Dean of the Faculty of Science and Technology, State University of Makassar, who have encouraged the author to complete the article on developing an attacking strategy in futsal.

\section{References}

Agras, H., Ferragut, C., \& Abraldes, J. A. (2016). Match analysis in futsal: A systematic review. International Journal of Performance Analysis in Sport, 16(2), 652-686. https://doi.org/10.1080/24748668.2016.11868915.

Ahmed, H., Davison, G., \& Dixon, D. (2017). Analysis of activity patterns, physiological demands and decision-making performance of elite Futsal referees during matches. International Journal of Performance Analysis in Sport, 17(5), 737-751. https://doi.org/10.1080/24748668.2017.1399321.

Aliyyah, Wicaksono, B., Saniatuzzulfa, R., \& Mukholid, A. (2020). Relevansi antara self efficacy dengan kecemasan sebelum bertanding pada atlet futsal putri. Jurnal SPORTIF : Jurnal Penelitian Pembelajaran, 6(1), 105-117.

Almeida, J., Sarmento, H., Kelly, S., \& Travassos, B. (2019). Coach decision-making in Futsal: from preparation to competition. International Journal of Performance Analysis in Sport, 19(5), 711-723. https://doi.org/10.1080/24748668.2019.1648717.

Apriantono, T., Herman, I., Hasan, M. F., Juniarsyah, A. D., Ihsani, S. I., \& Hidayat, I. I. (2018). Physical Activity Level Mapping of Senior High School Students in West Java Tommy. Jurnal Pendidikan Jasmani Dan Olahraga, 3(1), 122-128.

Ashari, R. F., \& Adi, S. (2019). Pengembangan Model Latihan Menyerang Futsal Menggunakan Formasi 3-1. Sport Science and Health, 1(2), 110-115.

Astuti, Y. (2017). The Power Contribution of Arm Muscle Strength and Eyes-Hand Coordination to Volleyball Set Up Passing Skill. Jurnal Pendidikan Indonesia, 6(2), 163-171. https://doi.org/10.23887/jpi-undiksha.v6i2.10005.

Boonsom, N. (2020). Effects of a combined stretching training on flexibility of students in sports science program Silpakorn University. Jurnal SPORTIF: Jurnal Penelitian Pembelajaran, 6(3), 599-611.

Borg, W. R., \& Gall, M. D. (1984). Educational research: An introduction.

Cosmin, D., \& Mircea, N. (2014). The development of futsal game at national level by implementing a strategic competitive and training management. Ovidius University Annals, Series Physical Educationa \& Sport/Science, Movement \& Health, XIV(2), 376-380.

de Freitas, V. H., Ramos, S. de P., Leicht, A., Alves, T., Rabelo, F., Bara-Filho, M. G., Guarnier, F. A., \& Nakamura, F. Y. (2017). Validation of the futsal-specific intermittent shuttle protocol for the simulation of the physical demands of futsal match-play. International Journal of Performance Analysis in Sport, 17(6), 934-947. https://doi.org/10.1080/24748668.2017.1409499.

Dinata, V. C., Priambodo, A., Hariyanto, A., Ristanto, O., \& Prakoso, B. (2020). Evaluasi penerapan blended learning berdasarkan kualitas model dan motivasi belajar mahasiswa-atlet Evaluation of the blended learning implementation based on model quality and student-athlete learning motivation PENDAHULUAN Pembalajaran tradisional tatap. Jurnal SPORTIF: Jurnal Penelitian Dan Pembelajaran, 6(2), 407422.

Duncan, S., Oppici, L., Borg, C., Farrow, D., Polman, R., \& Serpiello, F. R. (2018). Expertiserelated differences in the performance of simple and complex tasks: an event-related potential evaluation of futsal players. Science and Medicine in Football, 2(2), 157162. https://doi.org/10.1080/24733938.2017.1398408.

Dupri, D., Candra, O., Candra, A., \& Suryani, D. A. (2020). The Implementation of Problem Based Learning Model in Improving Cooperation and Learning Outcomes in Physical Education. Jurnal Pendidikan Jasmani Dan Olahraga, 5(1), 86-90. 
https://doi.org/10.17509/jpjo.v5i1.22531.

Fatchurrahman, F., Sudijandoko, A., \& Widodo, A. (2019). The comparison of the effect of ladder drills in out training and ladder drills ickey shuffle exercises on increasing speed and agility. Jurnal SPORTIF : Jurnal Penelitian Pembelajaran, 5(1).

Guntoro, T. S., Muhammad, J., \& Qomarrullah, R. (2020). Faktor kemampuan fisik dan psikologis penunjang keterampilan atlet elit sepakbola Propinsi Papua. Jurnal SPORTIF : Jurnal Penelitian Pembelajaran, 6(2), 390-406.

Nugroho, M. D., \& Tomoliyus. (2018). Validation of performance assessment instrument on futsal game in extracurricular activities. Jurnal SPORTIF: Jurnal Penelitian Pembelajaran, 5(2), 176-183.

Nur, L., Suherman, A., Subarjah, H., \& Budiana, D. (2019). Physical Education Learning Motivation: A Gender Analysis. Jurnal Pendidikan Jasmani Dan Olahraga, 4(1), 8-13. https://doi.org/10.17509/jpjo.v4i1.13790.

Purnomo, A., \& Hariono, A. (2020). Kepercayaan diri pada kemampuan smash tiga meter pada bolavoli Self-confidence due to ability of Three Meter Smash in Volleyball Volleyball is a sport that is played by twelve people on the field, the twelve people are divided into two teams, so each te. Jurnal SPORTIF: Jurnal Penelitian Pembelajaran, 6(2), 541-549.

Rahman, F. J. (2018). Peningkatan Daya Tahan, Kelincahan, dan Kecepatan pada Pemain Futsal: Studi Eksperimen Metode Circuit Training. Jurnal SPORTIF : Jurnal Penelitian Pembelajaran, 4(2), 264. https://doi.org/10.29407/js_unpgri.v4i2.12466.

Satrio, B., \& Winarno, M. E. (2019). Quality of sports physical fitness extracurricular participants. Jurnal SPORTIF: Jurnal Penelitian Pembelajaran, 5(2), 312. https://doi.org/10.29407/js_unpgri.v5i2.13069.

Sucipto, S. (2020). The Implementation of Tactical Approach in Developing Football Games Performance and Understanding of Junior High School Students. Jurnal Pendidikan Jasmani Dan Olahraga, 5(1), 70-75. https://doi.org/10.17509/jpjo.v5i1.23393.

Sumpena, A. (2017). Pengaruh Model Pembelajaran Personal (Personal Models) Terhadap Kepercayaan Diri Dan Hasil Belajar Bermain Futsal Siswa. Jurnal Pendidikan Jasmani Dan Olahraga, 2(1), 1. https://doi.org/10.17509/jpjo.v2i1.6395.

Williyanto, S., Santoso, N., Wiyanto, A., \& Article, H. (2020). Physical Education Teacher Strategies to Improving Student Learn- ing Outcomes Through Publication of Work Results. Journal of Physical Education, Health and Sport, 7(1), 5-10. 